\title{
Frações da matéria orgânica do solo sob pastagem, sistema plantio direto e integração lavoura-pecuária
}

\section{Fractions of soil organic matter under pasture, tillage system and crop-livestock integration}

\author{
Paulo Roberto Gazolla ${ }^{1}$; Roni Fernandes Guareschi²; Adriano Perin ${ }^{3}$; \\ Marcos Gervasio Pereira ${ }^{4}$; Celeste Queiroz Rossi ${ }^{5}$
}

\begin{abstract}
Resumo
Avaliou-se o carbono orgânico total e as frações químicas (ácido húmico - FAH, ácido fúlvico - FAF, humina - Hum) e granulométricas (carbono orgânico associado as partículas - COp, carbono orgânico associado aos minerais - COam e índice de manejo do carbono - IMC) da matéria orgânica do solo (MOS) em amostras de um Latossolo Vermelho sob sistema plantio direto (SPD) com integração lavoura-pecuária (ILP), em comparação à uma área em SPD sem ILP e áreas de Cerrado natural (CE) e pastagem (PA) no sudoeste de Goiás. Amostras de solo foram coletadas nas camadas de $0-5 ; 5-10 ; 10$ 20 e 20-40 cm, em delineamento inteiramente casualizado. Dentre as áreas cultivadas, a ILP apresentou nas camadas superficiais do solo os maiores teores de COT, COp, COam, Hum e relação C-FAH/C-FAF, tendo sido verificados valores de COT, COp, COam e Hum semelhantes aos quantificados na área de CE nas camadas mais profundas do solo. Em algumas profundidades avaliadas, as áreas de SPD e ILP apresentaram maior IMC em comparação à área de PA. As áreas de SPD e PA não apresentaram diferença no COT, COam e relação C-FAH/C-FAF, no entanto, a área de SPD conferiu maior estabilidade da MOS, pela similaridades nos teores de $\mathrm{C}$ da Hum, FAH, COp e IMC em relação às áreas de CE e ILP em algumas profundidades avaliadas.

Palavras-chave: Carbono orgânico do solo, sistemas de manejo, substâncias húmicas, Latossolo, cerrado
\end{abstract}

\begin{abstract}
The aim of this study was to evaluate the total organic carbon and the chemical (humic acid - FAH, fulvic acid - FAF, humin - Hum) and textural (organic carbon associated particles - COp, organic carbon associated with minerals - COam and carbon management index - IMC) of soil organic matter $(\mathrm{SOM})$ in samples of an Oxisol under no-tillage (NT) with crop-livestock integration (ILP), compared to one NT area without ILP and areas of natural Cerrado (CE) and pasture (PA) in southwestern Goiás. Soil samples were collected in the $0-5,5-10,10-20$ and $20-40 \mathrm{~cm}$ in a completely randomized design. Among the cultivated areas the ILP presented in the upper soil layers the highest COT, COp, COam, Hum C-FAH/C-FAF and respect, having been checked in COT, COp, and COam Hum similar to those quantified in CE area in the deeper layers of the soil. In some depths evaluated, areas of NT and ILP
\end{abstract}

1 Tecnólogo em produção de grãos, M.e em Ciências Agrárias, Dept ${ }^{\circ}$ de Fitotecnia, Instituto Federal Goiano, Campus Rio Verde, IF Goiano, Rio Verde, GO. E-mail: paulorgazolla@hotmail.com

2 Tecnólogo em Produção de Grãos, Pós-Doutorando em Ciência do Solo, Dept ${ }^{\circ}$ de Solos, Universidade Federal Rural do Rio de Janeiro, UFRRJ, Seropédica, RJ. E-mail: guareschiecotarelli@hotmail.com

3 Prof. Dr., Dept ${ }^{\circ}$ de Solos, UFRRJ, Seropédica, RJ. E-mail: perinrj@yahoo.com.br

4 Prof. Dr., Dept ${ }^{\circ}$ de Fitotecnia, IF Goiano, Campus Rio Verde, Rio Verde, GO. E-mail: gervasio@ufrrj.br

5 Eng $^{\mathrm{a}}$ Agr $^{\mathrm{a}}$, Pós-Doutoranda em Ciência do Solo, Dept ${ }^{\mathrm{o}}$ de Solos, UFRRJ, Seropédica, RJ. E-mail: celesteq.rossi@yahoo.com.br Autor para correspondência 
had higher IMC compared to PA area. Areas of NT and PA showed no statistical difference in the COT, COam and C-FAH/C-FAF relationship, however, the NT area proved to be forwarding to greater stability of SOM, as it showed similarities in levels $\mathrm{C}$ of Hum, FAH, COp and IMC in relation to areas of CE and ILP in some depths evaluated.

Key words: Soil organic carbon, management systems, humic substances, Oxisol, cerrado

\section{Introdução}

Com a expansão da fronteira agrícola, a qual ocasiona a remoção da vegetação nativa, por meio da mecanização intensiva e o uso de práticas de manejo inadequadas, alteram-se os atributos edáficos. Estas consequências levam a degradação do solo, reduzindo a produtividade, principalmente devido aos processos erosivos em conjunção a redução do conteúdo de nutrientes e da matéria orgânica (ZINN; DIMAS; SILVA, 2002; LAL, 2003). A reversão dessa degradação do solo pode ser realizada por meio de práticas conservacionistas do solo, como o sistema plantio direto (SPD) e/ou integração lavoura-pecuária (ILP) (MORETI et al., 2007; LOSS et al., 2011a). Nestes sistemas, ocorre a manutenção de resíduos vegetais na superfície, somada à ausência de revolvimento do solo; além da redução da emissão de $\mathrm{CO}_{2}$, e aumento do estoque de carbono no solo (LOSS et al., 2011a; GUARESCHI; PEREIRA; PERIN, 2012), trazendo ainda benefícios, tais como: aumento da diversidade microbiana, melhoria da fertilidade e dos atributos físicos do solo (SIX et al., 2002; FOLEY et al., 2005; SALTON et al., 2008; CHÁVEZ et al., 2011).

As substâncias húmicas ( $\mathrm{SH})$, que representam uma das frações da matéria orgânica do solo (MOS) são consideradas indicativas dos processos e do grau de humificação da MOS, sendo subdivididas nas frações ácidos fúlvicos (FAF), ácidos húmicos (FAH) e humina (Hum) (NASCIMENTO et al., 2010). Variações na distribuição das formas das SH podem indicar o impacto do sistema de manejo na qualidade do solo. Alguns estudos demonstram que a Hum é a mais abundante em solos de Cerrado ou em solos manejados, enquanto as frações ácido fúlvico (FAF) e fração ácido húmico $(\mathrm{FAH})$ variam de acordo com o manejo adotado e a profundidade do solo (FONTANA et al., 2006; PASSOS et al., 2007; SOUZA; MELO, 2003).

Ao avaliarem as SH sob ILP, pastagem (PA), SPD e vegetação nativa em um Latossolo Vermelho de Maracaju, MS, Silva et al. (2011) constataram que a adição de $\mathrm{C}$ às $\mathrm{SH}$, no sistema ILP foi maior em comparação aos demais sistemas de manejo avaliados. De maneira similar, Loss (2011) e Rossi et al. (2011), ao avaliarem áreas de ILP no estado de Goiás também verificaram que a introdução de braquiária no cultivo da soja em SPD, proporcionou alteração nos teores de carbono e de suas frações químicas.

O fracionamento granulométrico da matéria orgânica do solo (MOS) é baseado no grau de associação da MOS com a matriz do solo, ou seja, o carbono pode estar livre ou fracamente associado às partículas de solo, sendo chamado de carbono orgânico particulado (COp); ou estar fortemente ligado às partículas minerais, formando complexos organo-minerais (COam). Desta forma, a utilização de sistemas de manejo que promovam diferentes aportes de biomassa vegetal pode ser identificada por meio da fração particulada da MOS, sendo possível esta ser utilizada como ferramenta para avaliar a qualidade do solo, principalmente em um curto período de tempo (CONCEIÇÃO et al., 2005; ROSSI et al., 2012). Apesar da importância da determinação desta fração, ainda são poucos os trabalhos com fracionamento físico e químico em solos do Cerrado, desta forma torna-se necessário identificar as suas diferentes frações, bem como suas formas de proteção sob vegetação natural e diferentes sistemas de manejo neste Bioma.

Diante o exposto, observa-se que a inclusão de gramíneas na ILP torna-se uma alternativa a mais 
para o aporte de resíduos vegetais ao solo, em comparação aos demais sistemas de manejo como o SPD. No entanto, ainda existem poucas informações na literatura que apresentem a contribuição deste sistema nas mudanças das frações da MOS. Desta forma, avaliou-se neste trabalho o carbono orgânico total e as frações químicas e granulométricas da matéria orgânica do solo (MOS) em Latossolo Vermelho sob sistema plantio direto (SPD) com integração lavoura-pecuária (ILP), em comparação à uma área em SPD sem ILP e áreas de Cerrado natural e pastagem, no sudoeste de Goiás.

\section{Material e Métodos}

O estudo foi realizado em área de Cerrado, nos municípios de Rio Verde (17 $47^{\circ} \mathrm{S}$; $50^{\circ} 55^{\prime}$ $\mathrm{W}$ e altitude $780 \mathrm{~m})$ e Montividiu $\left(17^{\circ} 27^{\prime} \mathrm{S} ; 51^{\circ}\right.$ 04' W e altitude de $930 \mathrm{~m}$ ), localizados na região sudoeste de Goiás. Como principais características das áreas em estudo destacam-se a altitude de 890 m e o clima, identificado como clima tropical quente, Aw segundo Köppen, e estação chuvosa e seca bem definida, precipitação com média anual de $1740 \mathrm{~mm}$. O relevo da área é predominantemente plano e os solos das áreas de estudo, em ambos os municípios, foram classificados como Latossolo Vermelho Distroférrico (EMBRAPA, 2006).

Em setembro de 2009 (estação seca), foram analisadas quatro áreas de cultivo, a saber: Sistema de Integração Lavoura Pecuária (ILP), Sistema de Plantio Direto (SPD), Pastagem plantada (não cultivada) de Brachiaria decumbens (PA) e um cerrado nativo (CE) "stricto sensu", tomado como referência. Todas as áreas encontram-se em torno de $4 \mathrm{~km}$ de distância entre si.

O cerrado analisado está localizado dentro da área de reserva da Fazenda Vargem Grande (S $17^{\circ}$ 21' 49,9"; W $051^{\circ} 28$ ' 37,9"; altitude 951m). A área de pastagem plantada de $B$. decumbens (S $17^{\circ} 21^{\text {' }}$ 17,8"; W $051^{\circ} 28$ ' 47,8"; altitude $938 \mathrm{~m}$ ), vem sendo cultivada com uma taxa de lotação aproximada de 2 unidade animal (bovinos) por hectare e apresenta 10 anos de exploração. A área de ILP (S 17 19' 27,3"; W 051 29' 29,3"; altitude $962 \mathrm{~m}$ ) foi implantada no ano de 1999. Antes da instalação do ILP, a área foi manejada por 7 anos com sistema de preparo convencional (1985-1991) para o cultivo de grãos (milho, feijão, soja e girassol) e com SPD com rotação de culturas - milho, soja, algodão, feijão (1991-1998). Na ILP, a braquiária (B. ruziziensis) é semeada em consórcio ao milho safrinha, para intensificar a produção de palhada no período seco do ano. Para isto, após a colheita do milho, é feita a introdução de bovinos na área (2,0 unidade animal por hectare), com permanência dos animais por 90 dias (julho a setembro). Após a retirada dos animais, permanecem apenas as touceiras de braquiária na área. Em seguida, espera-se que ocorram as primeiras chuvas e realiza-se uma adubação em cobertura na braquiária com $200 \mathrm{~kg} \mathrm{ha}^{-1}$ do formulado NPK (20:00:20) a lanço na primeira quinzena de setembro. Após a rebrota, quando a área estará totalmente coberta pela capineira, é feita a dessecação e o plantio das culturas anuais. Já a área de SPD (S 17² 25' 16,6”; W $051^{\circ} 23^{\prime}$ ' 8, 1"; altitude $933 \mathrm{~m}$ ), possui um histórico de 20 anos de cultivo convencional com plantio de soja no verão e milho safrinha, sendo o SPD adotado em 1999.

A adubação básica das principais culturas dos sistemas agrícolas foram as seguintes: 1) ILP - a) algodão (verão) - $500 \mathrm{~kg} \mathrm{ha}^{-1}$ da fórmula NPK 1030-10; b) milho safrinha: $450 \mathrm{~kg} \mathrm{ha}^{-1} \mathrm{da}$ formulação NPK 07-28-14, no plantio e $100 \mathrm{~kg} \mathrm{ha}^{-1}$ de uréia, em cobertura aos $25 \mathrm{DAE}$; 2) SPD - a) soja (verão) - $430 \mathrm{~kg} \mathrm{ha}^{-1}$ da fórmula NPK 02-20-18; b) milho safrinha: $330 \mathrm{~kg} \mathrm{ha}^{-1}$ da fórmula NPK 08:20:18 e $100 \mathrm{~kg} \mathrm{ha}^{-1}$ de uréia, em cobertura aos 25 DAE. O SPD recebeu calagem no ano de 2007, utilizando-se uma dose de 2,5 $\mathrm{Mg} \mathrm{ha}^{-1}$ de calcário dolomítico, já o ILP recebeu calagem no ano de 2005, utilizando-se uma dose de 3,60 $\mathrm{Mg} \mathrm{ha}^{-1}$ de calcário dolomítico. Já a área de PA, anualmente (durante a estação chuvosa) recebe adubação nitrogenada $\left(100 \mathrm{~kg} \mathrm{ha}^{-1}\right.$ de uréia) e recebeu uma aplicação de $2 \mathrm{Mg} \mathrm{ha}^{-1}$ de calcário dolomítico no ano 2007. 
Em cada área foi demarcada uma gleba representativa de 2,25 ha $(150 \times 150 \mathrm{~m})$, e em cada uma delas foram abertas cinco trincheiras de aproximadamente $1 \times 1 \mathrm{~m}$ de superfície e 0,4 m de profundidade em posição aleatória dentro das glebas. O delineamento utilizado foi inteiramente casualizado. Em cada uma das trincheiras, nas diferentes áreas, foi realizada a coleta de amostras indeformadas, com auxílio de um anel volumétrico
(EMBRAPA, 1997), nas profundidades de 0-5, 5-10, $10-20$ e $20-40 \mathrm{~cm}$. Nessas mesmas profundidades, foram coletadas amostras deformadas, as quais foram secas ao ar, destorroadas e passadas em peneira de $2 \mathrm{~mm}$ de malha, obtendo-se a terra fina seca ao ar, na qual foi realizada a caracterização química e análise granulométrica (EMBRAPA, 1997) (Tabela 1).

Tabela 1. Atributos químicos e análise granulométrica das áreas avaliadas. Rio Verde - GO, 2010.

\begin{tabular}{|c|c|c|c|c|c|c|c|c|c|c|c|c|}
\hline \multirow{2}{*}{ Área } & $\mathrm{pH}$ & $\mathrm{P}$ & $\mathrm{Ca}$ & $\mathrm{Mg}$ & $\mathrm{K}^{+}$ & $\mathrm{Al}$ & $\mathrm{H}+\mathrm{Al}$ & $\mathrm{T}$ & $\mathrm{V}$ & Argila & Silte & Areia \\
\hline & $\mathrm{H}_{2} \mathrm{O}$ & $\mathrm{mg} \mathrm{kg}^{-1}$ & \multicolumn{6}{|c|}{----------------- cmol k kg-1 } & $-\%-$ & \multicolumn{3}{|c|}{-------- $\mathrm{g} \mathrm{kg}^{-1}$----------- } \\
\hline & \multicolumn{12}{|c|}{$0-5 \mathrm{~cm}$} \\
\hline${ }^{*} \mathrm{CE}$ & 4,53 & 4,15 & 1,69 & 1,30 & 0,20 & 0,6 & 11,77 & 18,0 & 17,4 & 594,0 & 12,0 & 394,0 \\
\hline PA & 5,40 & 2,76 & 2,46 & 2,22 & 0,46 & 0,0 & 6,10 & 11,2 & 45,3 & 577,0 & 81,0 & 342,0 \\
\hline SPD & 5,70 & 4,30 & 3,54 & 2,14 & 0,27 & 0,0 & 4,56 & 10,5 & 56,4 & 477,0 & 151,0 & 372,0 \\
\hline ILP & 5,70 & 6,23 & 5,34 & 1,94 & 0,18 & 0,0 & 5,57 & 13,2 & 56,3 & 475,0 & 128,0 & 397,0 \\
\hline \multicolumn{13}{|c|}{$5-10 \mathrm{~cm}$} \\
\hline $\mathrm{CE}$ & 4,40 & 1,70 & 0,73 & 1,00 & 0,09 & 0,9 & 10,50 & 15,0 & 12,0 & 521,0 & 85,0 & 394,0 \\
\hline PA & 5,27 & 1,86 & 2,17 & 1,65 & 0,14 & 0,2 & 6,37 & 10,3 & 38,1 & 561,0 & 133,0 & 306,0 \\
\hline SPD & 5,20 & 6,38 & 2,69 & 1,58 & 0,10 & 0,0 & 5,17 & 9,5 & 46,0 & 461,0 & 100,0 & 439,0 \\
\hline ILP & 5,00 & 9,42 & 2,05 & 1,16 & 0,11 & 0,3 & 7,75 & 11,0 & 29,7 & 625,0 & 145,0 & 230,0 \\
\hline \multicolumn{13}{|c|}{$10-20 \mathrm{~cm}$} \\
\hline $\mathrm{CE}$ & 4,20 & 0,78 & 0,48 & 1,17 & 0,05 & 0,9 & 8,69 & 12,1 & 14,1 & 554,0 & 102,0 & 344,0 \\
\hline PA & 5,20 & 1,60 & 1,73 & 1,22 & 0,05 & 0,2 & 5,99 & 9,0 & 32,8 & 561,0 & 100,0 & 339,0 \\
\hline SPD & 5,23 & 4,33 & 1,62 & 0,92 & 0,09 & 0,1 & 6,16 & 8,8 & 30,3 & 528,0 & 83,0 & 389,0 \\
\hline ILP & 4,60 & 3,09 & 1,13 & 0,85 & 0,08 & 0,6 & 7,86 & 9,9 & 20,9 & 692,0 & 111,0 & 197,0 \\
\hline \multicolumn{13}{|c|}{$20-40 \mathrm{~cm}$} \\
\hline $\mathrm{CE}$ & 4,4 & 1,35 & 0,49 & 0,75 & 0,03 & 0,5 & 6,66 & 7,9 & 18,0 & 628,0 & 85,0 & 287,0 \\
\hline PA & 5,4 & 1,15 & 1,24 & 1,05 & 0,04 & 0,1 & 4,40 & 6,7 & 34,0 & 477,0 & 67,0 & 372,0 \\
\hline SPD & 5,9 & 0,84 & 0,92 & 0,79 & 0,09 & 0,1 & 4,73 & 6,5 & 28,0 & 628,0 & 69,0 & 304,0 \\
\hline ILP & 4,5 & 0,72 & 0,64 & 0,91 & 0,05 & 0,5 & 5,67 & 7,2 & 22,0 & 709,0 & 95,0 & 197,0 \\
\hline
\end{tabular}

CE - cerrado nativo; PA - pastagem; SPD - sistema plantio direto; ILP - Integração lavoura pecuária.

Fonte: Elaboração dos autores.

A determinação do $\mathrm{C}$ orgânico foi realizada pelo método de oxidação por via úmida, com aquecimento externo, proposto por Yeomans e Bremner (1988). O fracionamento granulométrico da MOS foi realizado segundo Cambardella e Elliot (1992). Aproximadamente $20 \mathrm{~g}$ de solo e $60 \mathrm{~mL}$ de solução de hexametafosfato de sódio $\left(5 \mathrm{~g} \mathrm{~L}^{-1}\right)$ foram agitados durante 15 horas em agitador horizontal. A seguir, a suspensão foi passada por peneira de 53 $\mu \mathrm{m}$. O material retido na peneira carbono orgânico particulado (COp) foi seco em estufa a $50^{\circ} \mathrm{C}$, quantificado em relação a sua massa, moído em gral de porcelana e analisado em relação ao teor de C segundo Yeomans e Bremner (1988). O carbono orgânico associado aos minerais (COam) foi obtido a partir da diferença entre o COT e o COp. Também foi calculado o Índice de Manejo do Carbono (IMC) e de seus componentes, a partir da proposta original de Blair, Lefroy e Lisle (1995), que considera o COP representante da fração lábil do COT e o CAM como não lábil. 
Para a extração e o fracionamento químico das amostras de terra, foi utilizada a técnica de solubilidade diferencial (SWIFT, 1996), com adaptação de Benites, Madari e Machado (2003), obtendo-se o carbono orgânico na fração ácidos fúlvicos (FAF), fração ácidos húmicos (FAH) e humina (HUM). Para tal, pesou-se uma massa de terra que possuía $30 \mathrm{mg}$ de carbono orgânico submetidas ao contato com $20 \mathrm{~mL}$ de $\mathrm{NaOH} 0,1$ mol L-1 por um tempo de $24 \mathrm{~h}$ (extração alcalina EA). A separação entre o extrato alcalino $(\mathrm{EA}=$ FAF + FAH) e o resíduo foi feita por centrifugação a $5000 \mathrm{~g}$ por 30 minutos. Seguiu-se mais uma lavagem com a mesma solução anterior, juntando o extrato com o anteriormente obtido, resultando em volume final de aproximadamente $40 \mathrm{~mL}$. O resíduo foi reservado para determinação da humina (HUM). $\mathrm{O} \mathrm{pH}$ do extrato alcalino (EA) foi ajustado a 1,0 com $\mathrm{H}_{2} \mathrm{SO}_{4} 20 \%$, seguido de decantação por $18 \mathrm{~h}$. O precipitado (FAH) foi separado da fração solúvel (FAF) por filtragem e ambos os volumes aferidos a $50 \mathrm{ml}$ com água destilada.

A determinação quantitativa do carbono orgânico nas FAF e FAH foi feita usando alíquotas de 5,0 $\mathrm{mL}$ de extrato, $1,0 \mathrm{~mL}$ de dicromato de potássio 0,042 $\mathrm{mol} \mathrm{L}^{-1}$ e 5,0 $\mathrm{mL}$ de $\mathrm{H}_{2} \mathrm{SO}_{4}$ concentrado, em bloco digestor a $150{ }^{\circ} \mathrm{C}(30 \mathrm{~min})$ e titulação com sulfato ferroso amoniacal $0,0125 \mathrm{~mol} \mathrm{~L}^{-1}$. No resíduo, foi determinado o carbono orgânico na fração HUM, após secagem do material em estufa a $65^{\circ} \mathrm{C}$ (secagem completa) e adicionando $5,0 \mathrm{~mL}$ de dicromato de potássio $0,1667 \mathrm{~mol} \mathrm{~L}^{-1}$ e $10,0 \mathrm{~mL}$ de $\mathrm{H}_{2} \mathrm{SO}_{4}$ concentrado, em bloco digestor a $150^{\circ} \mathrm{C}$ (30min) e titulação com sulfato ferroso amoniacal 0,25 $\mathrm{mol} \mathrm{L}^{-1}$ (YEOMANS; BREMNER, 1988).

Para todos os dados em cada profundidade, foi feita a avaliação da normalidade dos dados (Kolmogorov-Smirnov - Ks), homogeneidade das variâncias dos erros pelo Teste de Cochran (Coch). Posteriormente, os resultados foram submetidos à análise de variância com aplicação do teste $\mathrm{F}$ e os valores médios comparados entre si pelo teste $\mathrm{t}$ a 5\%, com auxílio do programa ASSISTAT (SILVA; AZEVEDO, 2002).

\section{Resultados e Discussão}

Ocorreram diferenças estatísticas entre as áreas avaliadas para as variáveis carbono orgânico total (COT) $\left(\mathrm{g} \mathrm{kg}^{-1}\right)$, carbono orgânico particulado (COp), carbono orgânico associado aos minerais (COam) e índice de manejo de carbono (IMC) na maioria das camadas de solo estudadas (Tabela 2). Os maiores valores de COT na área CE ocorreram devido ao maior aporte de resíduos vegetais na superfície do solo, em função da vegetação presente na área, associado à ausência da ação antrópica. Numa situação estável, normalmente em solos sob vegetação nativa com baixo grau de antropização, os teores de MOS não apresentam grandes variações ao longo do tempo, à medida que as adições de $\mathrm{C}$ orgânico via resíduos vegetais e a sua conversão em MOS, são da mesma magnitude que as perdas de C orgânico pela mineralização da MOS, promovidas pela atividade microbiana (SANCHEZ, 1976). Resultados semelhantes foram relatados por Silva et al. (2011) e Loss (2011), que constataram maiores teores de COT em áreas de vegetação nativa quando comparadas á áreas de SPD e ILP.

Pode-se inferir que o maior conteúdo de COT da ILP em relação ao SPD e PA na camada superficial do solo ocorre devido a introdução de espécies forrageiras no sistema, ou seja, essas forrageiras acumulam mais biomassa vegetal do que as culturas agrícolas, cuja fitomasssa é, muitas vezes, insuficiente para a manutenção da cobertura do solo (LOSS et al., 2011a). Segundo Franzluebbers e Stuedemann (2008) na ILP, as pastagens possibilitam um incremento nos teores de carbono em função do alto desenvolvimento vegetal, tanto na parte aérea como nas raízes. Desta forma, o C oriundo do efeito combinado dos resíduos vegetais das culturas agrícolas e forrageiras na ILP supera o acúmulo de $\mathrm{C}$ derivado apenas de resíduos de gramíneas na PA e culturas agrícolas no SPD. Esse padrão também foi observado por Loss (2011) ao avaliar os teores de COT em áreas com diferentes sistemas de manejo. O autor também constatou que a área de ILP apresentou maior valor deste 
atributo em comparação à área de SPD. Segundo o autor, o consórcio da braquiária junto ao milho safrinha propicia a deposição de resíduos culturais de degradação mais lenta e, portanto, favorece o acúmulo de COT devido a sua maior relação $\mathrm{C} / \mathrm{N}$.

Tabela 2. Carbono orgânico total (COT) $\left(\mathrm{g} \mathrm{kg}^{-1}\right)$, carbono orgânico particulado (COp), carbono orgânico associado aos minerais (COam) e índice de manejo de carbono (IMC) entre os sistemas de manejo e as profundidades avaliadas. Rio Verde - GO, 2010.

\begin{tabular}{|c|c|c|c|c|}
\hline \multirow{3}{*}{ Profundidade $(\mathrm{cm})$} & \multicolumn{4}{|c|}{ Sistemas avaliados } \\
\hline & $\mathrm{CE}$ & PA & SPD & ILP \\
\hline & \multicolumn{4}{|c|}{$\operatorname{COT}\left(\mathrm{g} \mathrm{kg}^{-1}\right)$} \\
\hline $0-5$ & $103,36 \mathrm{a}$ & $47,90 \mathrm{c}$ & $44,87 \mathrm{c}$ & $73,62 \mathrm{~b}$ \\
\hline $5-10$ & $91,77 \mathrm{a}$ & $42,85 \mathrm{bc}$ & $37,31 \mathrm{c}$ & $52,94 \mathrm{~b}$ \\
\hline $10-20$ & $56,47 \mathrm{a}$ & $33,79 \mathrm{~b}$ & $31,77 \mathrm{~b}$ & $47,90 \mathrm{a}$ \\
\hline \multirow[t]{2}{*}{$20-40$} & $44,37 \mathrm{a}$ & $24,13 \mathrm{c}$ & $25,72 \mathrm{c}$ & $33,28 \mathrm{~b}$ \\
\hline & \multicolumn{4}{|c|}{$\mathrm{COp}\left(\mathrm{g} \mathrm{kg}^{-1}\right)$} \\
\hline $0-5$ & $78,42 \mathrm{a}$ & $19,48 \mathrm{c}$ & $21,25 \mathrm{c}$ & $28,90 \mathrm{~b}$ \\
\hline $5-10$ & $46,13 \mathrm{a}$ & $13,19 \mathrm{c}$ & $18,67 \mathrm{~b}$ & $20,86 \mathrm{~b}$ \\
\hline $10-20$ & $19,22 \mathrm{a}$ & $10,70 \mathrm{~b}$ & $12,20 \mathrm{~b}$ & $17,00 \mathrm{a}$ \\
\hline \multirow[t]{2}{*}{$20-40$} & $11,82 \mathrm{a}$ & $8,77 \mathrm{~b}$ & $11,74 \mathrm{a}$ & $12,20 \mathrm{a}$ \\
\hline & \multicolumn{4}{|c|}{ COam $\left(\mathrm{g} \mathrm{kg}^{-1}\right)$} \\
\hline $0-5$ & $24,95 \mathrm{~b}$ & $28,42 \mathrm{~b}$ & $23,62 \mathrm{~b}$ & $44,71 \mathrm{a}$ \\
\hline $5-10$ & 45,64 a & $29,66 \mathrm{ab}$ & $18,64 \mathrm{~b}$ & $32,09 \mathrm{ab}$ \\
\hline $10-20$ & $37,25 \mathrm{a}$ & $23,09 \mathrm{bc}$ & $19,57 \mathrm{c}$ & $30,90 \mathrm{ab}$ \\
\hline \multirow[t]{2}{*}{$20-40$} & $32,55 \mathrm{a}$ & $15,36 \mathrm{~b}$ & $13,97 \mathrm{~b}$ & $21,09 \mathrm{~b}$ \\
\hline & \multicolumn{4}{|c|}{ IMC } \\
\hline $0-5$ & 100 & $31,58 \mathrm{a}$ & $48,09 \mathrm{a}$ & $34,70 \mathrm{a}$ \\
\hline $5-10$ & 100 & $37,53 \mathrm{~b}$ & $94,22 \mathrm{a}$ & $62,99 \mathrm{ab}$ \\
\hline $10-20$ & 100 & $64,20 \mathrm{~b}$ & $71,79 \mathrm{~b}$ & $109,01 \mathrm{a}$ \\
\hline $20-40$ & 100 & $97,36 \mathrm{a}$ & $128,50 \mathrm{a}$ & $127,54 \mathrm{a}$ \\
\hline
\end{tabular}

Médias seguidas de mesma letra minúscula na linha não diferem significativamente entre os diferentes sistemas de uso do solo pelo teste $\mathrm{t}$ a $5 \%$.

Fonte: Elaboração dos autores.

Não foram verificadas diferenças estatísticas para os valores de COT nas profundidades de 1020 e 20-40 cm entre as áreas de CE e ILP, o que demonstra que o cultivo do solo na forma de ILP, está aumentando, em profundidade, os teores de COT em comparação as áreas de SPD. Esse padrão pode ser atribuído ao consórcio do milho com a braquiária, que além de propiciar a deposição de resíduos culturais de degradação mais lenta, favorece maiores aportes de matéria orgânica pelo sistema radicular das gramíneas (milho e braquiária), com destaque para a braquiária, que possui sistema radicular bem desenvolvido e distribuído ao longo do perfil do solo.

Nota-se ainda que, independentemente da profundidade avaliada, as áreas de PA e SPD sempre mantiveram valores semelhantes de COT. Diversos trabalhos têm demonstrado esse padrão (D'ANDRÉA et al., 2004; ROZANE et al., 2010). Tal fato pode ser atribuído, porque de maneira similar ao observado para a área de SPD, a área de PA possui elevada capacidade de acúmulo de MOS pelo não revolvimento do solo. Adicionalmente a grande produção de biomassa vegetal na superfície 
do solo e principalmente pela intensa renovação do sistema radicular abundante e permanente também podem estar contribuindo para esse padrão (SALTON, 2005).

Independentemente do sistema de manejo avaliado, está ocorrendo uma redução nos teores de COT em profundidade. Esse efeito já foi relatado por diversos trabalhos (FREITAS et al., 2000; FREIXO et al., 2002, D'ANDREA et al., 2004), sendo decorrente da menor exposição dessas camadas a ação dos organismos decompositores da MOS associado ao menor aporte.

Os maiores valores de COp da área de $\mathrm{CE}$ em relação aos demais sistemas manejados nas camadas superficiais do solo pode ser atribuído ao seu maior teor de C e aporte de resíduos vegetais na superfície. Segundo Loss et al. (2011b) e Rossi et al. (2011), sistemas de manejo e culturas que proporcionam maior aporte de $\mathrm{C}$ e resíduos na superfície do solo aumentam os teores de COp, visto que grande parte deste compartimento é formado por partículas derivadas de resíduos de plantas.

Os maiores conteúdos de COp da ILP entre os sistemas manejados, bem como a semelhança nos valores de COp entre as áreas de ILP e CE (1020 e $20-40 \mathrm{~cm}$ ) pode ser decorrente da utilização da braquiária junto ao cultivo do milho safrinha, pois este manejo diferenciado propicia uma maior adição anual e manutenção dos resíduos vegetais na superfície do solo quando comparado ao SPD e PA. Resultados semelhantes foram relatados por Loss (2011) e Rossi et al. (2012), em que ao avaliarem áreas de SPD com e sem ILP em Latossolo Vermelho no estado de Goiás, constataram maiores valores de COp em áreas de ILP em relação ao SPD. Da mesma forma, Carmo et al. (2012) ao avaliarem as frações da matéria orgânica sob SPD com gramíneas, verificaram que a introdução de forrageiras no consórcio com o milho elevou o COp em relação ao cultivo de milho em SPD sem ILP. Diante o exposto, pode-se inferir que os teores de COp são dependentes da adição de resíduos vegetais ao solo, ou seja, o sistema de uso do solo com ILP está propiciando maior adição de resíduos na superfície do solo via palhada e, em profundidade, via sistema radicular até a camada de $20 \mathrm{~cm}$ quando comparado com as áreas de SPD e PA.

A similaridade dos teores de COp da área de SPD com as áreas de ILP e CE na camada de 20-40 cm pode ser atribuído ao constante aporte de resíduos vegetais na superfície do solo.

O maior conteúdo de COam da ILP em relação as demais áreas avaliadas na camada superficial do solo, bem como, a semelhança nos valores desta variável entre a ILP e CE nas demais profundidades, se dá devido ao maior aporte de resíduos vegetais oriundos de gramíneas (Tabela 2). As gramíneas apresentam uma maior relação $\mathrm{C} / \mathrm{N}$ e lignina/N, o que acarretara uma decomposição mais lenta do resíduo e o que favorece o aumento dos teores de $\mathrm{C}$ ligados a argila e silte, formando complexos organominerais (SILVA; MENDONÇA, 2007). Loss (2011) menciona que a utilização de braquiária na ILP, pode acarretar, juntamente com os óxidos da fração argila (Fe e Al), melhores condições para a formação de microagregados e assim com maiores proporções de microagregados tem-se também maiores teores de COam protegido nestes. A similaridade nos valores de COam entre às áreas de SPD e PA em todas as profundidades avaliadas, pode ser decorrente dos teores semelhantes de COT e COp entre estas áreas (Tabela 2). Já os maiores valores de COam do CE em comparação as áreas de PA e SPD (5-10; 1020 e $20-40 \mathrm{~cm}$ ) deve-se a nesse sistema de manejo terem sido verificados maiores teores de COT e por não ter sido submetido à revolvimento do solo, promovendo desta forma, uma maior estabilização da matéria orgânica na fração mineral. Resultados semelhantes foram relatados por Loss (2011) e Rossi et al. (2012), onde ao avaliarem áreas de SPD com e sem ILP em Latossolo Vermelho no estado de Goiás constataram maiores valores de COam em áreas de $\mathrm{CE}$ em relação aos demais sistemas de manejo. 
Os maiores valores de Índice de Manejo de Carbono (IMC) das áreas de SPD e ILP em comparação a área de PA (Tabela 2), devem-se a rotação de culturas e maior aporte de resíduos vegetais depositados ao solo nestes sistemas, ou seja, esses dois fatores estão contribuindo para o aumentado da quantidade e qualidade da MOS. Segundo Vieira (2007), o IMC está diretamente relacionada ao aporte de resíduos vegetais no sistema. Este autor observou que sistemas de cultura que envolvem leguminosas, apresentaram mais altos valores de IMC do que sistemas constituídos essencialmente por plantas de espécies gramíneas. Já os maiores valores de IMC na camada de 10-20 $\mathrm{cm}$ da área de ILP em relação aos demais sistemas de manejo, podem ser explicados devido aos seus maiores teores de $\mathrm{C}$ nesta camada, ou seja, o consórcio do milho com braquiária favorece maiores aportes de matéria orgânica pelo sistema radicular das gramíneas (milho e braquiária), com destaque para a braquiária, que possui sistema radicular bem desenvolvido e distribuído ao longo do solo.

Dentre as frações da MOS, a Hum foi a que se apresentou em maiores teores em relação as demais, independente da área estudada e profundidade analisada (Tabela 3). Em diversos estudos em solos tropicais também se observou predomínio do carbono da fração humina em relação às outras frações (ASSIS; JUCKSCH; SÁ; NEVES, 2006; BARRETO et al., 2008; LOSS et al., 2009; ROSSI et al., 2011; SILVA et al., 2011; ROSSI et al., 2012). Os elevados valores de Hum podem estar relacionados ao tamanho das moléculas e ao maior grau de estabilidade desta fração (FONTANA et al., 2006). Segundo Fontana et al. (2006), as FAF e FAH, por apresentarem menor estabilidade, podem ser translocadas para camadas mais profundas, serem polimerizadas ou mineralizadas, e diminuir, assim, seu teor residual no solo.
De maneira geral, a área de $\mathrm{CE}$ se destacou das demais, ou seja, apresentou maiores teores de Hum (0-5 e 5-10 cm), FAF (0-5; 10-20 e 20-40 $\mathrm{cm})$ e FAH (todas as profundidades) (Tabela 3 ). Este padrão pode ser atribuído ao maior aporte de serapilheira e ausência da influência antrópica nesta área, apresentando o mesmo padrão do COT. Em ambientes naturais, a formação das substâncias húmicas é atrelada à atividade microbiana (MACHADO; GERZABECK, 1993), sendo a humificação, ao longo do tempo, o resultado final do processo microbiológico. Resultados semelhantes foram relatados por Loss (2011) que também encontrou maiores teores das $\mathrm{SH}$ em áreas de $\mathrm{CE}$ em relação a áreas de SPD e ILP.

Em relação às áreas cultivadas, observou-se que a ILP apresentou maiores teores de Hum (0-5; 5-10; 10-20 cm) em relação ao SPD e PA, apresentando valores semelhantes ao $\mathrm{CE}$ nas profundidades de 10-20 e 20-40 cm (Tabela 3). Esses maiores teores de Hum quantificados na área de ILP em relação as demais podem ser atribuídos à maior produção de resíduos vegetais com maior relação $\mathrm{C} / \mathrm{N}$ e lignina/N, os quais possuem decomposição mais lenta do resíduo e favorecem o aumento de frações recalcitrantes no solo (SILVA; MENDONÇA, 2007). Outra justificativa seria devido ao denso sistema radicular das gramíneas, que em contato com as partículas minerais contribuem à estabilização da MOS (RASSE; RUMPEL; DIGNAC, 2005; ROSSI et al., 2011), pois segundo esses autores, o $\mathrm{C}$ derivado de raízes tem um tempo médio de residência 2,4 vezes maior que o $\mathrm{C}$ derivado da parte aérea, e a contribuição das raízes para a MOS é cerca de $30 \%$ maior que a da parte aérea. 
Tabela 3. Carbono da fração humina (Hum), ácido fúlvico (FAF) e ácido húmico (FAH) e relação ácido húmico e ácido fúlvico (C-FAH/C-FAF) nos diferentes sistemas de uso do solo. Rio Verde - GO, 2010.

\begin{tabular}{|c|c|c|c|c|}
\hline \multirow{3}{*}{$\begin{array}{l}\text { Sistemas } \\
\text { avaliados }\end{array}$} & \multicolumn{3}{|c|}{ Carbono das frações húmicas $\left(\mathrm{g} \mathrm{kg}^{-1}\right)$} & \multirow{2}{*}{$\begin{array}{c}\text { C-FAH/ C-FAF } \\
\left(\mathrm{g} \mathrm{kg}^{-1}\right)\end{array}$} \\
\hline & Hum & FAF & FAH & \\
\hline & & $0,0-5,0 \mathrm{~cm}$ & & $0,0-5,0 \mathrm{~cm}$ \\
\hline $\mathrm{CE}$ & $37,70 \mathrm{a}$ & $4,11 \mathrm{a}$ & $7,89 \mathrm{a}$ & $1,97 \mathrm{ab}$ \\
\hline PA & $11,38 \mathrm{c}$ & $2,27 \mathrm{~b}$ & $2,93 \mathrm{~b}$ & $1,33 \mathrm{~b}$ \\
\hline SPD & $12,25 \mathrm{c}$ & $2,01 \mathrm{~b}$ & $2,32 \mathrm{~b}$ & $1,19 \mathrm{~b}$ \\
\hline \multirow[t]{2}{*}{ ILP } & $20,28 \mathrm{~b}$ & $1,09 \mathrm{c}$ & $2,75 \mathrm{~b}$ & $2,60 \mathrm{a}$ \\
\hline & & $5,0-10,0 \mathrm{~cm}$ & & $5,0-10,0 \mathrm{~cm}$ \\
\hline $\mathrm{CE}$ & $28,43 \mathrm{a}$ & $2,84 \mathrm{a}$ & $6,10 \mathrm{a}$ & $2,17 \mathrm{a}$ \\
\hline PA & $8,45 \mathrm{c}$ & $1,74 \mathrm{~b}$ & $1,83 \mathrm{c}$ & $1,08 \mathrm{~b}$ \\
\hline SPD & $11,98 \mathrm{c}$ & $2,12 \mathrm{ab}$ & $2,20 \mathrm{bc}$ & $1,06 \mathrm{~b}$ \\
\hline \multirow[t]{2}{*}{ ILP } & $21,85 \mathrm{~b}$ & $2,12 \mathrm{ab}$ & $2,58 \mathrm{~b}$ & $1,23 \mathrm{~b}$ \\
\hline & & $10,0-20,0 \mathrm{~cm}$ & & $10,0-20,0 \mathrm{~cm}$ \\
\hline $\mathrm{CE}$ & $12,15 \mathrm{a}$ & $5,35 \mathrm{a}$ & $6,14 \mathrm{a}$ & $1,11 \mathrm{a}$ \\
\hline PA & $6,53 \mathrm{~b}$ & $1,56 \mathrm{c}$ & $1,50 \mathrm{c}$ & $0,95 \mathrm{ab}$ \\
\hline SPD & $7,78 \mathrm{~b}$ & $2,71 \mathrm{~b}$ & $1,65 \mathrm{bc}$ & $0,62 \mathrm{~b}$ \\
\hline \multirow[t]{2}{*}{ ILP } & $12,55 \mathrm{a}$ & $2,22 \mathrm{bc}$ & $2,37 \mathrm{~b}$ & $1,15 \mathrm{a}$ \\
\hline & & $20,0-40,0 \mathrm{~cm}$ & & $20,0-40,0 \mathrm{~cm}$ \\
\hline $\mathrm{CE}$ & $10,10 \mathrm{a}$ & $4,71 \mathrm{a}$ & $4,39 \mathrm{a}$ & $0,93 \mathrm{a}$ \\
\hline PA & $5,65 \mathrm{~b}$ & $1,18 \mathrm{~b}$ & $1,46 \mathrm{~b}$ & $1,07 \mathrm{a}$ \\
\hline SPD & $6,78 \mathrm{ab}$ & $1,27 \mathrm{~b}$ & $1,11 \mathrm{~b}$ & $0,92 \mathrm{a}$ \\
\hline ILP & $9,25 \mathrm{ab}$ & $1,73 \mathrm{~b}$ & $1,70 \mathrm{~b}$ & $1,04 \mathrm{a}$ \\
\hline
\end{tabular}

*Médias seguidas de mesma letra minúscula na coluna não diferem significativamente entre os diferentes sistemas de uso do solo pelo teste t a $5 \%$.

Fonte: Elaboração dos autores.

Esses maiores valores de carbono na Hum da ILP em relação aos demais sistemas cultivados, podem acarretar maior expressão das propriedades da fração coloidal da matéria orgânica, tais como: retenção da umidade, melhor agregação do solo e maior retenção de cátions, características de grande importância quando se trata do cultivo de sistemas sustentáveis de produção (SOUZA; MELO, 2003). Alguns trabalhos na literatura também constataram maiores valores de $\mathrm{C}$ na fração Hum em áreas de ILP em relação ao SPD (LOSS, 2011; ROSSI et al., 2011; SILVA et al., 2011).

De maneira similar ao observado para os valores de COT, as áreas de SPD e PA apresentaram valores semelhantes das $\mathrm{SH}$ em praticamente todas as profundidades avaliadas (Tabela 3). Este padrão demonstra mais uma vez a semelhança entre essas duas áreas no que se diz respeito à dinâmica da MOS.
A semelhança destas áreas pode ser decorrente do bom manejo da pastagem adotado na área PA e do tempo de implantação do SPD, pois sabe-se que o acúmulo de $\mathrm{C}$ em SPD ocorre muito lentamente, levando de 10 a 15 anos para se tornar expressivo (BAYER; MIELNICZUK, 2008; CARVALHO et al., 2009).

O SPD apresentou valores de C da Hum (20-40 $\mathrm{cm})$, FAF (5-10; 10-20 e 20-40 cm) e FAH (todas as profundidades) semelhantes à área de ILP (Tabela 3). Diante disso, percebe-se que o SPD, rotação de culturas, manutenção dos resíduos culturais na superfície do solo, proporciona decomposição lenta do material vegetal depositado, o que pode com o passar do tempo, encaminhar este sistema de manejo a estabilização da MOS e consequentemente melhorias dos atributos químicos e físicos do solo. 
Somente foi verificada diferença estatística para a relação C-FAH/C-FAF entre as áreas de estudo nas profundidades de 0-5, 5-10 e 10-20 cm (Tabela 3). Na camada superficial do solo $(0-5 \mathrm{~cm})$, a área de ILP apresentou valores da relação C-FAH/CFAF semelhantes aos observados na área de $\mathrm{CE}$ e superiores as áreas de SPD e PA. Esses valores da relação C-FAH/C-FAF da área de ILP e CE são próximos de 2, indicando que, nestas áreas, há predomínio de C-FAH em relação aos C-FAF, apresentando um material orgânico mais estável. A manutenção de maiores teores de C-FAH em detrimento aos teores de C-FAF evidencia solos mais preservados, de manejo mais conservacionista (CANELLAS et al., 2003). No entanto, esse padrão restringe-se apenas a camada superficial $(0-5 \mathrm{~cm})$, pois na camada de $5-10 \mathrm{~cm}$, os sistemas manejados (PA, SPD e ILP) apresentaram relação C-FAH/CFAF semelhantes entre si e inferiores ao CE (Tabela 3). A maior relação C-FAH/C-FAF do CE devese ao seu maior teor de C total e C- FAH. Já os valores próximos de 1 dos sistemas manejados (PA, SPD e ILP) demonstram segundo alguns autores (EBELING et al., 2004; GIÁCOMO; PEREIRA; BALIEIRO, 2008) um material de qualidade ótima, que permitiria o estabelecimento de atributos físicos e químicos favoráveis ao desenvolvimento de plantas.

Na camada de 10-20 cm, as áreas de CE, PA e ILP apresentaram valores da relação C-FAH/C-FAF semelhantes entre si, e apenas as áreas de CE e ILP proporcionaram maiores valores desta relação em comparação a área de SPD. Esse resultado pode ser decorrente dos maiores conteúdos de MOS das áreas de CE e ILP em relação ao SPD, ou seja, esse fator esta corroborando para um maior equilíbrio entre as frações da MOS tendendo seus valores para mais próximos de 1 .

\section{Conclusões}

Dentre as áreas cultivadas, a ILP apresentou nas camadas superficiais do solo os maiores teores de
COT, COp, COam, Hum e relação C-FAH/C-FAF, e valores de COT, COp, COam e Hum semelhantes a área de CE nas camadas mais profundas do solo.

Nas profundidades 5-10 e 10-20, as áreas de SPD e ILP apresentaram maior IMC em comparação a área de PA, evidenciando a contribuição desses sistemas na melhoria da quantidade e qualidade da MOS.

As áreas de SPD e PA não apresentaram diferença no COT, COam, SH e relação C-FAH/CFAF, no entanto, a área de SPD apresentou maior estabilidade da MOS, pela similaridade nos teores de $\mathrm{C}$ da Hum, FAH, COp e IMC em relação às áreas de CE e ILP.

\section{Referências}

ASSIS, C. P.; JUCKSCH, I.; SÁ, M. E.; NEVES, J. C. L. Carbono e nitrogênio em agregados de Latossolo submetido a diferentes sistemas de uso e manejo. Pesquisa Agropecuária Brasileira, Brasília, v. 41, n. 10, p. 1541-1550, 2006.

BARRETO, A. C.; FREIRE, M. B. G. S.; NACIF, P. G. S.; ARAÚJO, Q. R.; FREIRE, F. J.; INÁCIO, E. S. B. Fracionamento químico e físico do carbono orgânico total em um solo de mata submetido a diferentes usos. Revista Brasileira de Ciência do Solo, Viçosa, MG, v. 32, n. 4, p. 1471-1478, 2008.

BAYER, C.; MIELNICZUK, J. Fundamentos da matéria orgânica do solo. In: SANTOS, G. A.; SILVA, L. S.; CANELLAS, L. P.; CAMARGO, F. A. O. Ecossistemas tropicais e subtropicais. 2. ed. Porto Alegre: Metrópole, 2008. p. 7-18.

BENITES, V. M.; MADARI, B.; MACHADO, P. L. O. A. Extração e fracionamento quantitativo de substâncias húmicas do solo: um procedimento simplificado de baixo custo. Rio de Janeiro: Ministério da Agricultura, Pecuária e Abastecimento, 2003. 7 p.

BLAIR, G. J.; LEFROY, R. D. B.; LISLE, L. Soil carbon fractions based on their degree of oxidation, and the development of a carbon management index for agricultural systems. Australian Journal of Agricultural Research, Melbourne, v. 46, n. 1, p. 1459-1466, 1995.

CAMBARDELLA, C. A.; ELLIOT, E. T. Particulate soil organic-matter changes across a grassland cultivation sequence. Soil Science Society of American Journal, Netherlands, v. 56, n. 3, p. 777-783, 1992. 
CANELLAS, L. P.; VELLOSO, A. C. X.; MARCIANO, C. R.; RAMALHO, J. F. G. P.; RUMJANEK, V. M.; REZENDE, C. E.; SANTOS, G. A. Propriedades químicas de um Cambissolo cultivado com cana-deaçúcar, com preservação do palhiço e adição de vinhaça por longo tempo. Revista Brasileira de Ciência do Solo, Viçosa, MG, v. 27, n. 5, p. 935-944, 2003.

CARMO, F. F.; FIGUEIREDO, C. C.; RAMOS, M. L. G.; VIVALDI, L. J.; ARAÚJO, L. G. Frações granulométricas da matéria orgânica em latossolo sob plantio direto com gramineas. Bioscience Journal, Uberlândia, v. 28, n. 3, p. 420-431, 2012.

CARVALHO, J. L. N.; CERRI, C. E. P.; FEIGL, B. J.; PICOLlO, M. C.; GODINHO, V. P.; CERRI, C. C. Carbon sequestration in agricultural soils in the Cerrado region of the Brazilian Amazon. Soil Tillage Resherch, Amsterdam, v. 103, n. 2, p. 342-349, 2009.

CHÁVEZ, L. F.; ESCOBAR, L. F.; ANGHINONI, I.; CARVALHO, P. C. F.; MEURER, E. J. Diversidade metabólica e atividade microbiana no solo em sistema de integração lavoura-pecuária sob intensidades de pastejo. Pesquisa Agropecuária Brasileira, Brasília, v. 46, n. 10, p. 1254-1261, 2011.

CONCEIÇÃO, P. C.; AMADO, T. J. C.; MIELNICZUK, J.; SPAGNOLLO, E. Qualidade do solo em sistemas de manejo avaliada pela dinâmica da matéria orgânica e atributos relacionados. Revista Brasileira de Ciência do Solo, Viçosa, MG, v. 29, n. 5, p. 777-788, 2005.

D’ANDRÉA, A. F.; SILVA, M. L. N.; CURI, N.; GUILHERME, L. R. G. Estoque de carbono e nitrogênio e formas de nitrogênio mineral em um solo submetido a diferentes sistemas de manejo. Pesquisa Agropecuária Brasileira, Brasília, v. 39, n. 2, p. 179-186, 2004.

EBELING, A. G.; ESPINDULA JUNIOR, A.; VALLADARES, G. S.; ANJOS, L. H. C.; PEREIRA, M. G. Propriedades químicas como indicadores ambientais em organossolos do Estado do Rio de Janeiro. Revista Universidade Rural: Série Ciências da Vida, Seropédica, v. 24, n. 1, p. 1-6, 2004.

EMPRESA BRASILEIRA DE PESQUISA AGROPECUÁRIA - EMBRAPA. Manual de métodos de análise de solo. 2. ed. Rio de Janeiro: EMBRAPA Solos, 1997. 212 p.

Sistema brasileiro de classificação de solos. 2. ed. Rio de Janeiro: EMBRAPA Solos, 2006. 306 p.

FOLEY, J. A.; DEFRIES, R.; ASNER, G. P.; BARFORD, C.; BONAN, G.; CARPENTER, S. R.; CHAPIN, F. S.; COE, M. T.; DAILY, G. C.; GIBBS, H. K.; HELKOWSKI, J. H.; HOLLOWAY, T.; HOWARD, E. A.; KUCHARIK, C. J.; MONFREDA, C.; PATZ, J. A.;
PRENTICE, I. C.; RAMANKUTTY, N.; SNYDER, P. K. Global consequences of land use. Science, New York, v. 309, n. 5734, p. 570-574, 2005.

FONTANA, A.; PEREIRA, M. G.; LOSS, A.; CUNHA, T. J. F.; SALTON, J. C. Atributos de fertilidade e frações húmicas de um Latossolo Vermelho no Cerrado. Pesquisa Agropecuária Brasileira, Brasília, v. 41, n. 5, p. 847-853, 2006.

FRANZLUEBBERS, A. J.; STUEDEMANN, J. A. Early response of soil organic fractions to tillage and integrated crop-livestock production. Soil Science Society of America Journal, Madison, v. 72, n. 5, p. 613-625, 2008.

FREITAS, P. L.; BLANCANEAUX, P. H.; GAVINELLI, E.; LARRÉ-LARROUY, M. C.; FELLER, C. Nível e natureza do estoque orgânico de Latossolos sob diferentes sistemas de uso e manejo. Pesquisa Agropecuária Brasileira, Brasília, v. 35, n. 1, p. 157-170, 2000.

FREIXO,A.A.; MACHADO, P. L. O.A.; GUIMARÃES, C. M.; SILVA, C. A.; FADIGAS, F. S. Estoques de carbono e nitrogênio e distribuição de frações orgânicas de Latossolo do Cerrado sob diferentes sistemas de cultivo. Revista Brasileira de Ciências do Solo, Viçosa, v. 26, n. 1, p. 425-434, 2002.

GIÁCOMO, R. G.; PEREIRA, M. G.; BALIEIRO, F. C. Estoques de carbono e nitrogênio e distribuição das frações húmicas no solo sob diferentes coberturas florestais. Revista Brasileira de Ciências Agrárias, Recife, v. 3, n. 1, p. 42-48, 2008.

GUARESCHI, R. F.; PEREIRA, M. G.; PERIN, A. Deposição de resíduos vegetais, matéria orgânica leve, estoques de carbono e nitrogênio e fósforo remanescente sob diferentes sistemas de manejo no cerrado goiano. Revista Brasileira de Ciência do Solo, Viçosa, MG, v. 36, n. 3, p. 1-10, 2012.

LAL, R. Global potential of carbon sequestration to mitigate the greenhouse effect. Critical Review in Plant Science, Philadelphia, v. 22, n. 2, p. 151-184, 2003.

LOSS, A. Dinâmica da matéria orgânica, fertilidade e agregação do solo em áreas sob diferentes sistemas de uso no cerrado goiano. 2011. Tese (Doutorado em Ciência do Solo) - Universidade Federal Rural do Rio de Janeiro, Seropédica.

LOSS, A.; PEREIRA, M. G.; GIÁCOMO, S. G.; PERIN, A.; ANJOS, L. H. C. Agregação, carbono e nitrogênio em agregados do solo sob plantio direto com integração lavoura pecuária. Pesquisa Agropecuária Brasileira, Brasília, v. 46, n. 10, p. 1269-1276, 2011a.

LOSS, A.; PEREIRA, M. G.; SCHULTZ, N.; ANJOS, L. H. C. dos; SILVA, E. M. R. Carbono e frações granulométricas da matéria orgânica do solo sob sistemas 
de produção orgânica. Ciência Rural, Santa Maria, v. 39, n. 4, p. 1077-1082, 2009.

Frações orgânicas e índice de manejo de carbono do solo em diferentes sistemas de produção orgânica. Idesia, Chile, v. 29, n. 2, p. 11-19, 2011b.

MACHADO, P. L. O. A.; GERZABEK, M. Tillage and crop rotation interactions on humic substances of a typic haplorthox from southern Brazil. Soil Tillage Research, Amsterdam, v. 26, n. 1, p. 227-236, 1993.

MORETI, D.; ALVES, M. C.; VALÉRIO FILHO, W. V.; CARVALHO, M. P. Atributos químicos de um Latossolo Vermelho sob diferentes sistemas de preparo, adubações e plantas de cobertura. Revista Brasileira de Ciência do Solo, Viçosa, MG, v. 31, n. 1, p. 167-175, 2007.

NASCIMENTO, P. C.; LANI, J. L.; MENDONÇA, E. S.; ZOFFOLI, H. J. O.; PEIXOTO, H. T. M. Teores e características da matéria orgânica de solos hidromórficos do Espírito Santo. Revista Brasileira de Ciência do Solo, Viçosa, MG, v. 34, n. 1, p. 339-348, 2010.

PASSOS, R. R.; RUIZ, H. A.; MENDONÇA, E. S.; CANTARUTTI, R. B.; SOUZA, A. P. Substâncias húmicas, atividade microbiana e carbono orgânico lábil em agregados de um Latossolo Vermelho distrófico sob duas coberturas vegetais. Revista Brasileira de Ciência do solo, Viçosa, MG, v. 31, n. 1, p. 1119-1129, 2007.

RASSE, D. P.; RUMPEL, C.; DIGNAC, M. F. Is soil carbon mostly root carbon? Mechanisms for a specifc stabilisation. Plant and Soil, Netherlands, v. 269, n. 1, p. 341-356, 2005.

ROSSI, C. Q.; PEREIRA, M. G.; GIÁCOMO, S. G.; BETTA, M.; POLIDORO, J. C. Frações húmicas da matéria orgânica do solo cultivado com soja sobre palhada de braquiária e sorgo. Bragantia, Campinas, v. 70, n. 3, p. 622-630, 2011.

Frações lábeis da matéria orgânica em sistema de cultivo com palha de braquiária e sorgo. Revista Ciência Agronômica, Fortaleza, v. 43, n. 3, p. 38-46, 2012.

ROZANE, D. E.; CENTURION, J. F.; ROMUALDO, L. M.; TANIGUCHI, C. A. K.; TRABUCO, M.; ALVES, A. U. Estoque de carbono e estabilidade de agregados de um Latossolo Vermelho distrófico, sob diferentes manejos. Bioscience Journal, Uberlândia, v. 26, n. 1, p. 24-32, 2010.

SALTON, J. C. Matéria orgânica e agregação do solo na rotação lavoura-pastagem em ambiente tropical. 2005. Tese (Doutorado em Ciência do Solo) - Programa de Pós-Graduação em Ciência do Solo. Universidade Federal do Rio Grande do Sul, Porto Alegre.
SALTON, J. C.; MIELNICZUK, J.; BAYER, C.; BOENI, M.; CONCEIÇÃO, P. C.; FABRICIO, A. C.; MACEDO, M. C. M.; BROCH, D. L. Agregação e estabilidade de agregados do solo em sistemas agropecuários em Mato Grosso do Sul. Revista Brasileira de Ciência do Solo, Viçosa, MG, v. 32, n. 1, p. 11-21, 2008.

SANCHEZ, P. Properties and management of soils in the tropics. New York: John Wiley, 1976. 618 p.

SILVA, E. F.; LOURENTE, E. P. R.; MARCHETTI, M. E.; MERCANTE, F. M.; FERREIRA, A. K. T.; FUJI, G. C. Frações lábeis e recalcitrantes da matéria orgânica em solos sob integração lavoura-pecuária. Pesquisa Agropecuária Brasileira, Brasília, v. 46, n. 10, p. 1321 1331, 2011.

SILVA, F. de A. S. E.; AZEVEDO, C. A. V. de. Versão do programa computacional Assistat para o sistema operacional Windows. Revista Brasileira de Produtos Agroindustriais, Campina Grande, v. 4, n. 1, p. 71-78, 2002.

SILVA, I. R.; MENDONÇA, E. S. Matéria orgânica do solo. In: NOVAIS, R. F.; ALVAREZ, V. V. H.; BARROS, N. F.; FONTES, R. L. F.; CANTARUTTI, R. B.; NEVES, J. C. L. (Ed.). Fertilidade do solo. Viçosa: Sociedade Brasileira de Ciência do Solo, 2007. p. 275-374.

SIX, J.; FELLER, C.; DENEF, K.; OGLE, S. M.; MORAES, J. C.; ALBRECHT, A. Soil organic matter, biota and aggregation in temperate and tropical soils effects of no-tillage. Agronomie, v. 22, n. 1, p. 755-775, 2002.

SOUZA, W. J. O.; MELO, W. J. Matéria orgânica de um Latossolo submetido a diferentes sistemas de produção de milho. Revista Brasileira de Ciência do Solo, Viçosa, MG, v. 27, n. 6, p. 1113-1122, 2003.

SWIFT, R. S. Organic matter characterization. In: SPARKS, D. L. Methods of soil analysis. Madison: SSSA, 1996. p. 1011-1069.

VIEIRA, F. C. B. Estoques e labilidade da matéria orgânica e acidificação de um argissolo sob plantio direto afetados por sistemas de cultura e adubação nitrogenada. 2007. Tese (Doutorado em Ciência do Solo) - Universidade Federal do Rio Grande do Sul, Porto Alegre.

YEOMANS, J. C.; BREMNER, J. M. A rapid and precise method for routine determination of organic carbon in soil. Communications in Soil Science and Plant Analysis, Philadelphia, v. 19, n. 13, p. 1467-1476, 1988.

ZINN, Y. L.; DIMAS, V. S.; SILVA, J. E. Soil organic carbon as affected by afforestation with Eucalyptus and Pinus in the Cerrado region of Brazil. Forest Ecology and Management, Amsterdam, v. 166, n. 3, p. 285-294, 2002. 